\title{
МОРФОЛОГИЧЕСКИЕ ОСОБЕННОСТИ РАЗЛИЧНЫХ ФИЗИОЛОГИЧЕСКИХ ВАРИАНТОВ ОККЛЮЗИОННЫХ ВЗАИМООТНОШЕНИЙ
}

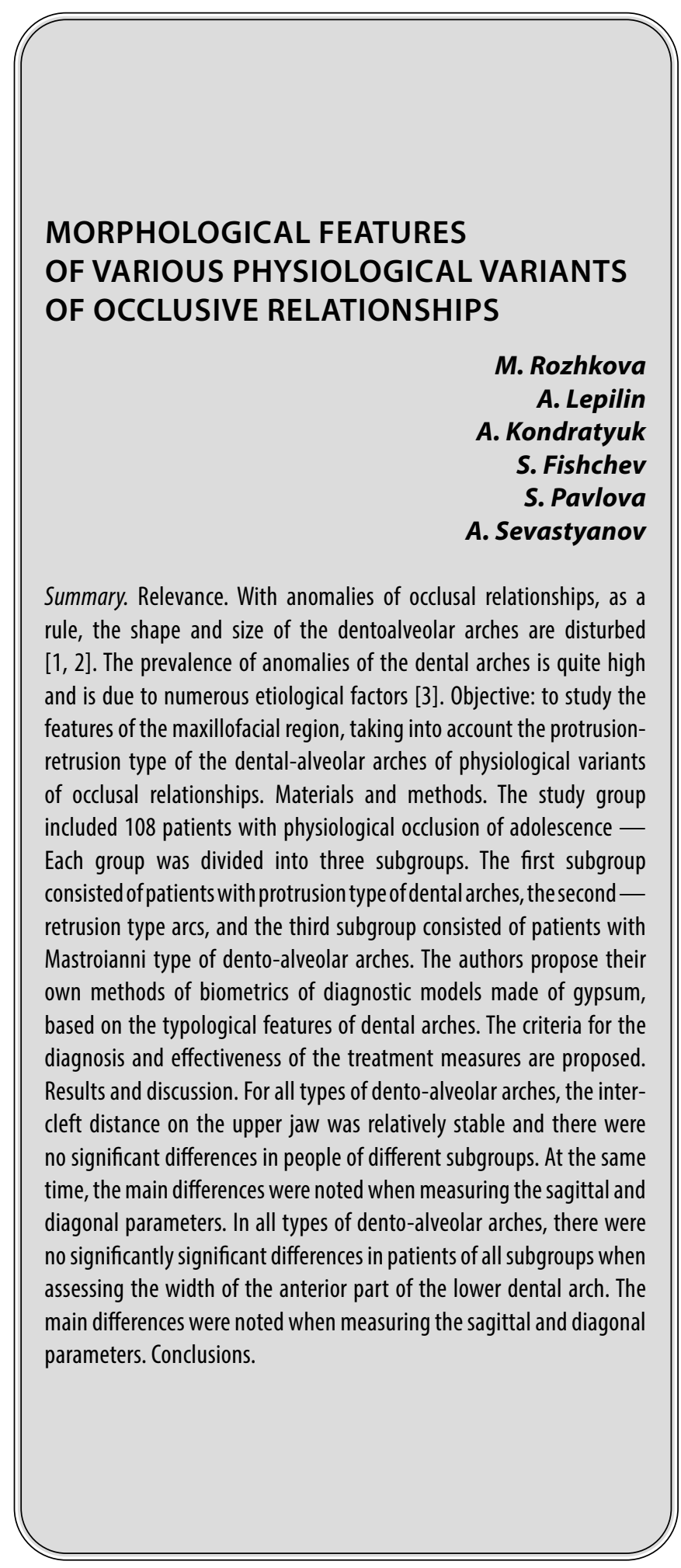

Рожкова Мария Геннадьевна

Ассистент, Санкт-Петербургский государственный педиатрический медицинский университет Министерства здравоохранения РФ rozmaria2010@yandex.ru

Лепилин Александр Викторович

Д.м.н., профессор, Саратовский государственный медицинский университет имени В.И. Разумовского Министерства здравоохранения РФ lepilins@mail.ru

Кондратюк Андрей Александрович Ассистент, Санкт-Петербургский государственный педиатрический медичинский университет Министерства здравоохранения РФ kondratyuk.andrey@icloud.com

Фищев Сергей Борисович

Д.м.н., профессор, Санкт-Петербургский государственный педиатрический медичинский университет Министерства здравоохранения РФ super.kant@yandex.ru

Павлова Светлана Георгиевна

К.м.н., ассистент, Санкт-Петербургский государственный педиатрический медицинский университет Министерства здравоохранения РФ

svetap_75@mail.ru

Севастьянов Аркадий Владимирович Д.м.н., дочент, Санкт-Петербургский государственный педиатрический медицинский университет Министерства здравоохранения РФ ardy.dkr@mail.ru

Аннотация. Актуальность. При аномалиях окклюзионных взаимоотношений, как правило, нарушается форма и размеры зубочелюстных дуг $[1,2]$. Распространённость аномалий дентальных дуг довольно высока и обусловлена многочисленными этиологическими факторами [3]. Цель исследования: изучить особенности челюстно-лицевой области с учетом протрузионно-ретрузионного типа зубо-альвеолярных дуг физиологических вариантов окклюзионных взаимоотношений. Материалы и методы. В группу исследования вошли пациенты с физиологической окклюзией подросткового возраста - 108 человек. В каждой группе выделено по три подгруппы. Первую подгруппу составили пациенты с протрузионным типом зубных дуг, вторую - ретрузионный тип дуг, а третью подгруппу составили пациенты с мезотрузионным типом денто-альвеолярных дуг. Предложены собственные методы биометрии диагностических моделей из гипса, основанные на типологических особенностях дентальных арок. Предложены критерии диагностики и эффективности проводимых лечебных мероприятий. Результаты и обсуждение. При всех типах 
A method for determining the convergence of antimirov in the dental arch, based on the intersection of conventional occlusal lines with the Central sagittal arch, passing through mezhrassovyy point and mid mimoletnoe of the distance measured between the vestibular-distal tubercles of the second permanent molars. To determine the position of the teeth in the vestibular-lingual direction, a method for measuring the incision angle at the intersection of the conditional median verticals of the antagonists on cone-beam computed tomograms, when combined with telerentgenograms in the lateral projection, is proposed.

Keywords: crowding of teeth, plaster models, dentition, orthodontic treatment. денто-альвеолярных арок, межклыковое расстояние на верхней челюсти было относительно стабильной величиной и не наблюдалось достоверных различий у людей различных подгрупп. В тоже время, основные различия отмечались при измерении сагиттальных и диагональных параметров.

При всех типах денто-альвеолярных арок, не было достоверно значимых различий у пациентов всех подгрупп при оценке показателей ширины переднего отдела нижней дентальной дуги. Основные различия отмечались при измерении сагиттальных и диагональных параметров. Выводы. Разработан метод определения конвергенции антимеров в дентальной арке, основанный на пересечении условных окклюзионных линий с центральной сагитталью зубной дуги, проходящей через межрезцовую точку и середину межмолярного расстояния, которое измерялось между вестибуло-дистальными бугорками вторых постоянных моляров. Для определения положения зубов в вестибулярно-язычном направлении предложен метод измерения межрезцового угла при пересечении условных срединных вертикалей антагонистов на конусно-лучевых компьютерных томограммах, при совмещении их с телерентгенограммами в боковой проекции.

Ключевые слова: скученность зубов, гипсовые модели, зубные ряды, ортодонтическое лечение.

классификации гнатических и дентальных типов лицевого отдела головы [8].

Однако существуют противоречивые мнения специалистов об использовании различных авторских методик при определении параметров зубных дуг в различных направлениях [9].

\section{Цель исслеАования}

Изучить особенности челюстно-лицевой области с учетом протрузионно-ретрузионного типа зубо-альвеолярных дуг физиологических вариантов окклюзионных взаимоотношений.

\section{материалы и метомы}

В группу исследования вошли пациенты с физиологической окклюзией подросткового возраста - 108 человек. В каждой группе выделено по три подгруппы. Первую подгруппу составили пациенты с протрузионным типом зубных дуг, вторую - ретрузионный тип дуг, а третью подгруппу составили пациенты с мезотрузионным типом денто-альвеолярных дуг.

В таблице 1 представлены пациенты в исследуемых подгруппах.

Настоящее исследование включало использование методов диагностики, общепринятых в клинической ортодонтии, которые включали измерения краниофа- 
Таблица 1. Количество пациентов в группе.

\begin{tabular}{|l|l|l|l|l|}
\multirow{2}{*}{ Группы исследования } & \multicolumn{4}{l|}{ Распределение пациентов по подгруппам: } \\
\cline { 2 - 6 } & $\mathbf{1}$ подгруппа & $\mathbf{2}$ подгруппа & 3 подгруппа & Итого \\
\hline ИТОГО & 32 & 29 & 47 & 108 \\
\hline
\end{tabular}

циального комплекса. Предложены собственные методы биометрии диагностических моделей из гипса, основанные на типологических особенностях дентальных арок. Предложены критерии диагностики и эффективности проводимых лечебных мероприятий.

Определяли основный периметр дентальной арки, проходящий по вестибулярной поверхности зубов, вблизи окклюзионного контура. Измерительные точки располагались на наиболее выпуклых поверхностях вестибулярного контура коронок зубов. Межрезцовая точка (центальная точка дентальной арки), расположенная на месте контакта медиальных резцов с вестибулярной стороны, являлась основным ориентиром для измерения в сагиттальном и диагональном направлении.

В трансверсальном направлении измеряли расстояние между вторыми молярами и между рвущими бугорками клыков. Диагональные размеры определяли от межрезцовой точки до клыков (передняя диагональ) и до вторых моляров (полная диагональ зубной арки). Глубина дентальной арки определялась от межрезцовой точки до линии, соединяющей вестибулярные дистальные бугорки вторых моляров.

Линейные размеры позволяли рассчитать индексные величины и параметры, характеризующие определённые типы дентальных арок и сопоставлять их с параметрами лица.

Для определения конвергенции антимеров в дентальной арке гипсовые модели фотографировали в окклюзионной норме с последующим нанесением основных ориентиров и реперных линий для расчетов.

Использовали точки, соответствующие расположению зубной вестибулярной дуги на резцах и премолярах. К тому же на язычной поверхности вблизи средней точки окклюзионного контура премоляров наносили ориентир для построения срединной окклюзионной линии. На середину окклюзионной поверхности моляров наносили точки с вестибулярной и язычной стороны, также для построения окклюзионных линий.

При биометрии моделей из гипса вызывали сложности определения межрезцового угла. Методика распила моделей с окрашиванием контуров зубов является громоздкой, трудоёмкой и имеет погрешности измерения. В связи с этим определение наклона зубов проводили с использованием данных конусно-лучевых компьютерных томограмм, которые получали на Корейском томографе Рax-i (VATECH Global), модели РНT-6500. Трехмерные изображения включали широкий спектр опций визуализации, а пакет прикладных программ позволял с высокой точностью проводить их измерения.

Одним из основных и обязательных методов исследования в клинической ортодонтии является телерентгенографический анализ краниофациальной области, как в прямой, так и в боковой проекциях. Телерентгенограммы в боковой проекции получали на аппарате Hitachi 450 с учетом общепринятых рекомендаций. Анализ проводили по стандартным методикам Шварца, Якобсона, Ди-Паоло используя основные ориентиры. Телерентгенограмма позволяла оценить положение челюстей и других частей головы относительно основных анатомических образований.

Для повышения качества диагностики и выделения типов зубных дуг по трузионному типу, проводилось совмещение фрагментов конусно-лучевых томографических снимков (сегмента резцов и сустава) с боковой телерентгенограммой головы. Межрезцовй угол варьировал от 125 до 145 градусов, что позволило нам использовать его в качестве ориентира, определяющего нейтральное положение резцов. При увеличении угла более 145 градусов, пациентов относили к группе людей с ретрузионным положением резцов, а при величине межрезцового угла менее 125 градусов - к протрузионному типу зубных дуг.

\section{Результаты \\ и обсужление}

При всех типах денто-альвеолярных арок, межклыковое расстояние на верхней челюсти было относительно стабильной величиной и не наблюдалось достоверных различий у людей различных подгрупп. В тоже время, основные различия отмечались при измерении сагиттальных и диагональных параметров.

Для людей с протрузионным типом дуг (1 подгруппа) величина фронтально-дистальной диагонали и глубина 


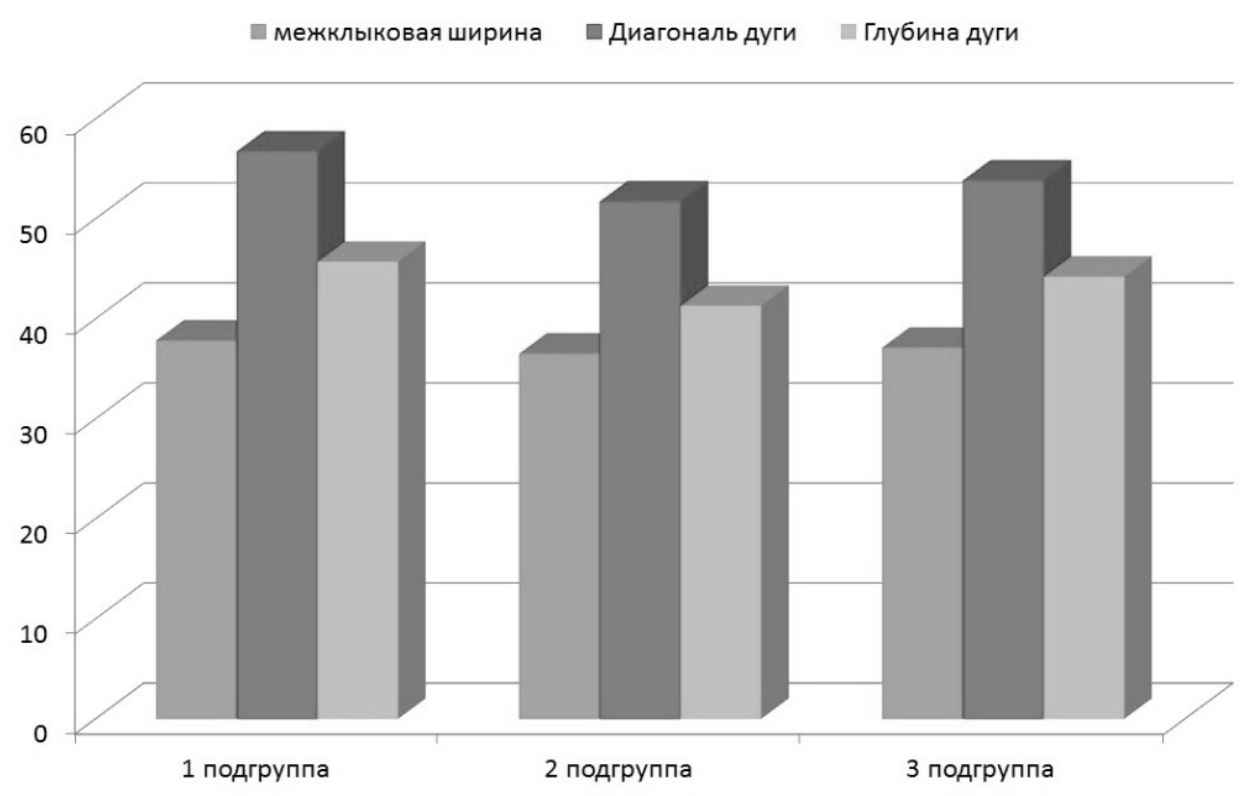

Рис. 1. Диаграмма параметров верхних зубо-альвеолярных дуг у людей группы сравнения в различных подгруппах

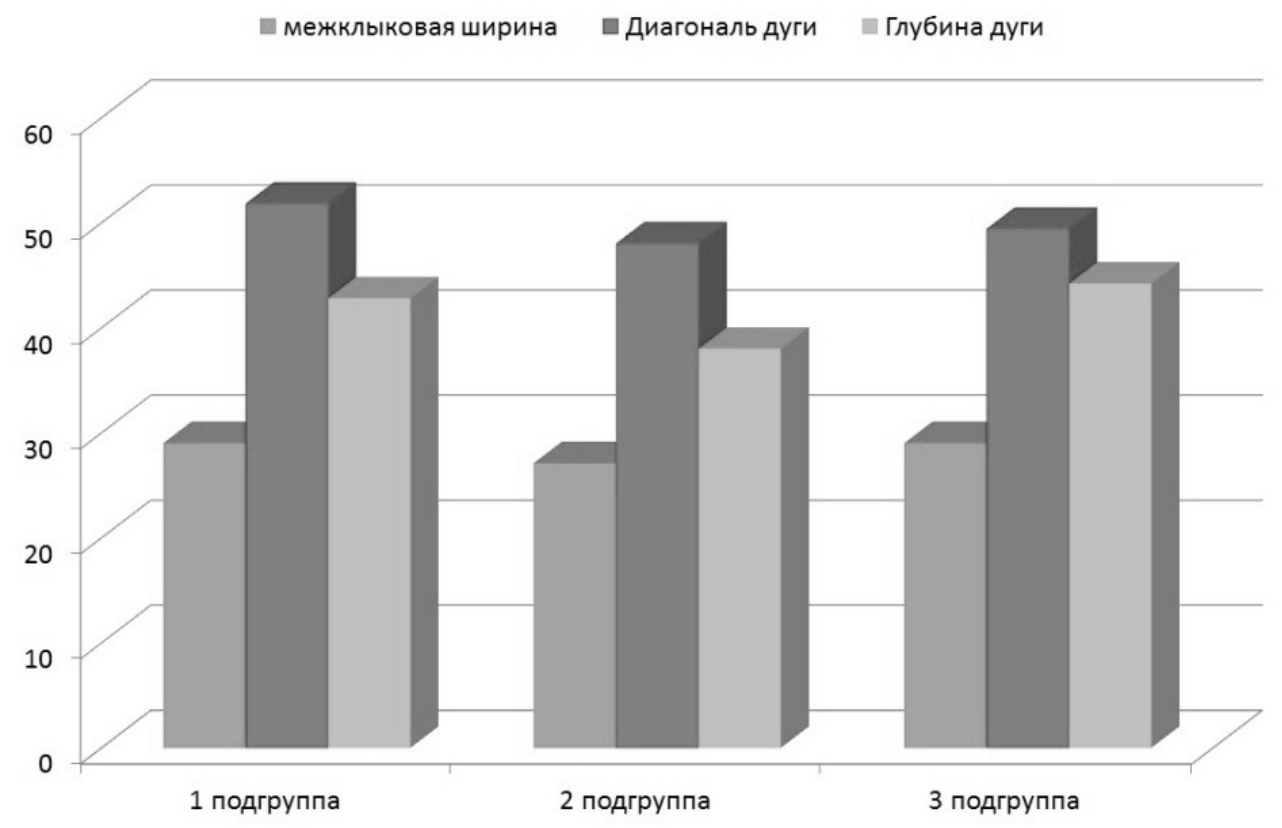

Рис. 2. Диаграмма параметров нижних зубо-альвеолярных дуг у лиц группы сравнения в различных подгруппах

дуги были достоверно больше, чем у людей с мезотрузионным (3 подгруппа) и, тем более, с ретрузионным (2 подгруппа) типом дентальных арок, что представлено на диаграмме (рис. 1).

Ширина переднего отдела верхних зубных дуг у лю-

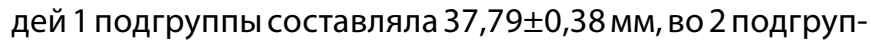

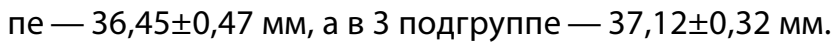

Результаты измерения диагональных параметров показали, что у людей 1подгруппы длина фронталь-

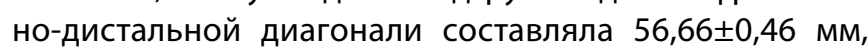
а при ретрузионном положении резцов (2 подгруппа) - 51,66 0,36 мм, что было достоверно меньше, чем у людей с физиологической протрузией резцов $(p \leq 0,05)$. При мезотрузионном типе дуг величина диа-

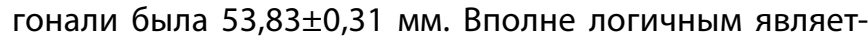


ся и разница в сагиттальных размерах, обусловленная различным торком зубов у пациентов исследуемых групп. Так, глубина дентальной дуги у пациентов 1, 2 и 3

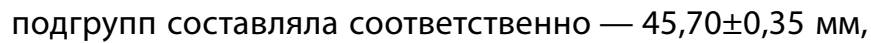
$41,33 \pm 0,29$ мм и 44,14 $\pm 0,36$ мм.

Та же закономерность прослеживалась при исследовании основных параметров нижних денто-альвеолярных арок.

При всех типах денто-альвеолярных арок, не было достоверно значимых различий у пациентов всех подгрупп при оценке показателей ширины переднего отдела нижней дентальной дуги. Основные различия отмечались при измерении сагиттальных и диагональных параметров.

Для людей с протрузионным типом дуг (1 подгруппа) величина фронтально-дистальной диагонали и глубина дуги были достоверно больше, чем у людей с мезотрузионным (3 подгруппа) и, тем более, с ретрузионным (2 подгруппа) типом дентальных арок, представленнных на диаграмме (рис. 2).

Ширина переднего отдела нижних зубных дуг у лю-

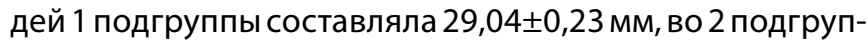

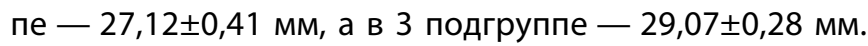
Показатели были достоверно меньше, чем на верхней челюсти у пациентов во всех подгруппах исследования.

Результаты измерения диагональных параметров показали, что у людей 1подгруппы длина фронталь-

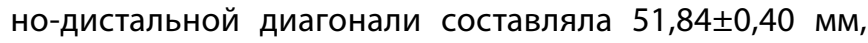
а при ретрузионном положении резцов (2 подгруп-

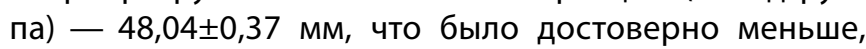
чем у людей с физиологической протрузией резцов $(p \leq 0,05)$. При мезотрузионном типе дуг величина диа-

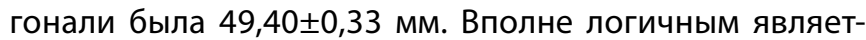
ся и разница в сагиттальных размерах, обусловленная различным торком зубов у пациентов исследуемых групп. Глубина зубной дуги у пациентов первой, второй и третьей подгрупп составляла, соответственно

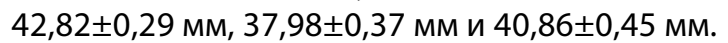

Таким образом, для зубных арок с протрузионным положением резцов при физиологической окклюзии характерно увеличение глубины дуги, а при ретрузии резцов - уменьшение сагиттальных размеров по сравнению с зубными дугами мезотрузионного типа.

Определено, что у людей с протрузионным типом дентальных дуг длина дуги, или сумма ширины коронок 14 зубов была больше, чем у людей с протрузионным типом дуг. В связи с тем, что достоверных различий в показателях трансверсальных размеров ширины зуюных дуг в областиседьмых зубов, нами не отмечено, соответственно индекс дентальной дуги при ретрузии резцов был больше, чем у людей с протрузионными зубными дугами. Кроме того, отношение длины дуги к диагональным размерам при всех типах дентальных арок составляло для верхней челюсти 2,12, а для нижней - 2,18, что можно использовать в качестве для диагностического критерия аномальных зубных арок.

Следует отметить, что у людей 1 подгруппы были характерны долихогнатические макро и микродонтные зубные дуги и мезогнатические микродонтные. В то же время у людей 2 подгруппы, как правило, были брахигнатические нормо- и микродентальные дуги и мезогнатические микродентальные типы. В 3 подгруппе, чаще встречались мезонатические нормодонтные дентальные дуги, и несколько реже долихогнатические микродонтные и брахигнатические макродонтные типы дентальных дуг, что и отражалось на показателях основным параметров дентальных арок. Тем не менее, для мезотрузионных типов дуг была характерна величина индекса дуги от 1,89 до 1,95 на верхнейчелюстной дентальной арке и от 1,95 до 1,99 зубной дуге нижней челюсти. Для протрузионного типа индекс верхней дуги был более 1,96, а нижней дуги - более 2,0. Ретрузионный тип дентальных арок характеризовался уменьшением показателей на верхней челюсти менее 1,88, а на нижней челюсти - менее 1,95.

\section{Выво $\triangle \mathrm{b}$}

1. Разработан метод определения конвергенции антимеров в дентальной арке, основанный на пересечении условных окклюзионных линий с центральной сагитталью зубной дуги, проходящей через межрезцовую точку и середину межмолярного расстояния, которое измерялось между вестибуло-дистальными бугорками вторых постоянных моляров. Для определения положения зубов в вестибулярно-язычном направлении предложен метод измерения межрезцового угла при пересечении условных срединных вертикалей антагонистов на конусно-лучевых компьютерных томограммах, при совмещении их с телерентгенограммами в боковой проекции.

2. У людей с мезотрузионным типом денто-альвеолярных дуг межрезцовый угол в среднем по под-

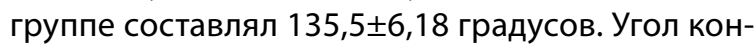

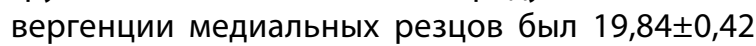
градуса. Латеральные резцы конвергировали

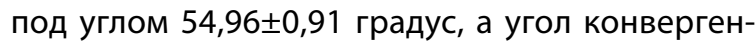
ции клыков приближался к прямому и составлял по подгруппе в среднем 91,12士 0,94 градуса. 
3. Протрузионный тип денто-альвеолярных дуг характеризовался уменьшением межрезцового угла до значений 117,5 55,76 градусов. При этом типе зубных дуг углы конвергенции передних зубов были достоверно больше, чем при ме- зотрузионном типе и составляли для медиаль-

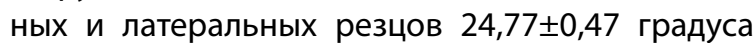
$60,11,84 \pm 0,94$ градусов, соответственно. Угол конвергенции клыков был больше прямого и в среднем по подгруппе составлял 96,84ะ1,03 градуса.

\section{ЛИТЕРАТУРА}

1. Лепилин А.В., Субботин Р.С., Фищев С.Б., Кондратюк А.А., Рубежов А.Л. Морфометрические параметры лица у пациентов с горизонтальной формой повышенной стираемости зубов // Морфология.— 2019.— № 2.—С. 176.

2. Рожкова М.Г., Галстян С.Г., Лепилин А.В., Севастьянов А.В., Фищев С.Б. Морфометрический метод исследования пациентов со скученностью зубов // Современная наука: актуальные проблемы теории и практики. Серия: Естественные и технические науки. — 2020.— № 7.— С. 192-196.

3. Фищев С.Б., Кондратюк А.А., Фомин И.В., Субботин Р.С., Лепилин А.В. Особенности торка медиальных резцов у людей с различными типами зубных дуг по результатам конусно-лучевых компьютерных томограмм // Стоматология детского возраста и профилактика. — 2019. — T. XIX. — № 1(69). C. $40-45$

4. Borodina V.V., Domenyuk D.A., Weisheim L.D., Dmitrienko S.V. Biometry of permanent occlusion dental arches — comparison algorithm for real and design indicators // Archiv EuroMedica. — 2018. — V. 8. — № 1.—P. 25-26. D0l: 10.35630/2199-885x/2019/9/3.29

5. Corrêa-Faria P. Ramos-Jorge M.L., Martins P.A. Malocclusion in preschool children: prevalence and determinant factors // Eur. Arch. Pediatric. Dent. — 2014. Vol. 15.— № 2.—P. 89-96. D0I: 10.1007/s40368-013-0069-9

6. Domenyuk D.A., Vedeshina E.G., Dmitrienko S.V. Shape individualization in lower dental arches drawn on basic morphometric features // Archiv EuroMedica. 2015.— T. 5.— № 1. - P. 11-15. D0I: 10.25207/1608-6228-2016-3-33-38

7. Domenyuk D.A., Shkarin V.V., Porfiriadis M.P., Dmitrienko D.S., Dmitrienko S.V. Classification of facial types in view of gnathology // Archiv euromedica. 2017. 一 T. 7. — № 1.— P. 8-13. D0I: 10.19163/1994-9480-2020-1(73)-20-24

8. Eslamipour F. Afshari Z., Najimi A. Prevalence of Malocclusion in Permanent Dentition of Iranian Population: A review Article // Iran. J. Public. Health.2018. — Vol. 47.— № 2.—P. 178-187. DOI: 10.1186/s40510-016-0120-6

9. Hagiwara Y. Uehara T., Narita T. Prevalence and distribution of anomalies of permanent dentition in 9584 Japanese high school students // 0dontology.2016. — Vol.104. — № 3. - P. 380-389. D0l: 10.1007/s10266-015-0225-2

10. Pillai J.P., Patel R.A., Banker A.M. Correlation between maxillary central incisor crown form and maxillary dental arch form: A Model-Based morphometric, cross-sectional study // J. Forensic Sci. Med. — 2018. — Vol. 4. — № 2. — P. 70-75. D0I 10.1590/S0103-6442012000200010

( Рожкова Мария Геннадьевна ( rozmaria2010@уandex.ru ), Лепилин Александр Викторович ( lepilins@mail.ru ), Кондратюк Андрей Александрович ( kondratyuk.andrey@icloud.com ), Фищев Сергей Борисович ( super.kant@yandex.ru ),

Павлова Светлана Георгиевна ( svetap_75@mail.ru), Севастьянов Аркадий Владимирович ( ardy.dkr@mail.ru).

Журнал «Современная наука: актуальные проблемы теории и практики» 